\title{
MJMR RELATIONSHIP BETWEEN SOCIAL MEDIA USAGE AND BODY IMAGE EVALUATION IN MALAYSIAN YOUTH
}

\author{
Sonia Khodabakhsh ${ }^{1 *}$, Chan Siaw Leng ${ }^{2}$ \\ ${ }^{1}$ Assistant Professor, Universiti Tunku Abdul Rahman (UTAR), Malaysia \\ ${ }^{2}$ Senior Lecturer, University Putra Malaysia (UPM), Sarawak, Malaysia \\ *Correspondence Author’s Email: soniak@utar.edu.my
}

\begin{abstract}
Social media is one of the most influential factors that highly relates to individuals' perspectives towards many things in their lives. Besides, in recent decades, one of the important concepts among the young population is how they evaluate their body image. Therefore, this study aimed at exploring the relationship between social media usage and body image evaluation among Malaysian youth. Three hundred sixteen participants completed the online questionnaires including demographic questionnaire, Social Media Intensity, and Body Image Evaluation questionnaire. Data were analysed by Pearson Correlation method and results showed that there is a negative relationship between social media usage and body image evaluation. It means that if youth use social media excessively, they may have a low evaluation of their body image and visa versa. This relationship is a correlation and should not be considered a causal relationship. This study has implications for young people and counsellors in the field by providing awareness about the association between these two concepts.
\end{abstract}

\section{Keywords: Bodyimage evaluation, Malaysia, Social media, Youth}

\section{INTRODUCTION}

Body image is the way people see or experience their physical selves, and the emotions produced by that perception may be either positive or negative because they can be affected by individual or environmental influences (Cash, 2004). People nowadays tend to have concerns over their body image, as they compare it with celebrities or influencers presented in social media due to the rising use of social media.

Social media is defined as a form of media that includes interaction with one another visually (Manning, 2014). Social media also are known as web-based applications that provide a function to share, group, having a conversation, and relationships (Kietzmann et al., 2011). Excessive use of social media has impacts on individuals'lives and their interpersonal relationships (Khodabakhsh \& Siak, 2018).

Media, in general, is found to be the strongest factor influencing the idealized body image on adolescent girls and boys (You \& Shin, 2019). There is also result stated that social media use related to body dissatisfaction is the same among boys and girls, even with the mediating effect of the parent-child relationship (de Vries et al., 2018). Peer's feedback on exercising to have a better body image influences the boys more than how models in social media, whereas girls will be affected by media celebrities easily (Silva et al., 2014). Young women tend to admire people in social media and vire them as role models rather than men (Heiman \& Olenik-Shemesh, 2018). Both studies have indicated that women are more likely than men to get influenced by celebrities or models presented in social media. While many people perceived women is much concerned about their body image, a study from (Cramblitt \& Pritchard, 2013) stated that when men spend more time on social media, especially in the category of sports or even health issues, men will reflect themselves on their body image as compared to the content in social media.

(Meshioye, 2016) investigated that media has an impact on body image on young adults. Another study conducted by (Puglia, 2017) mentioned the effect of social media on body esteem among young women. A study from (Hogue \& Mills, 2019) found that young adult females who are active with picture-based social media of influencing peers have more negative body 
image towards themselves.

In Malaysia, a study with 529 high school students from (Mellor et al., 2009) has discovered that body dissatisfaction is related to sex and ethnicity. For example, Chinese female students are prone to body dissatisfaction as compared to other ethnicities. BMI currently has become a good predictor for males who aim to be muscular, whereas peer influence, media messages are likely to influence females to lose weight in Malaysia (Mellor et al., 2009). This indicates social media has a high influence on body dissatisfaction, especially in females.

Social media is also a high impact factor which is linked to body image disturbance especially in women (Grabe et al., 2008). In a study by (Hogue \& Mills, 2019), active social media engagement with attractive peers can increase the chance of body dissatisfaction, especially in females. It seems that appearance comparison in social media has become a concern towards their body image in females (Hogue \& Mills, 2019). Hence, social media has a strong correlation with perceived body image, regardless of gender (Guonadottir \& Garoarsdottir, 2014; Kennedy, 2000; Vartanian et al., 2001).

According to Pew Research Centre (2018), social media has already influenced many users which around $71 \%$ of teenagers are using Facebook ages 13 to 17 years old globally, while Instagram and Snapchat users are reported as $52 \%$ and $41 \%$ respectively. Moreover, young people in Malaysia from any gender and ethnicity use social media nowadays (Khodabakhsh et al., 2020). According to (Oakes, 2019), body image and social media are correlated with photo-based activities such as posting pictures and scrolling news feed will lead to negative body image. Besides, viewing other users' profile photos of liking, forwarding or commenting on their photos on social networking sites frequently lead the individuals involved in social comparisons associated with the physical image, resulting in a negative feeling about their body image (Kim \& Chock, 2015). In (Hogue \& Mills, 2019) research, they discovered that 56 of 118 undergraduate female students in York university which chose to leave a comment on an attractive female peer in social media has a stronger relation to negative body image. This image from social media has rapidly caused people wanting to have a better body image and disliked their current body image much, which gives a negative body image on themselves. (Muhlheim, 2019).

According to the social comparison theory, people tend to compare themselves with others. There are two types of social comparison which are upward social comparison in which people compare themselves to those better than them, and downward social comparison in which people compare themselves with those who are worse than them. People sometimes compare themselves to others as a way of increasing their sense of gratitude or as motivation, however, negative comparison can lead to having a false sense of self or less motivated (Cherry, 2019).

\section{METHODOLOGY}

\section{Research Design}

This research is a quantitative cross-sectional design to explore the relationship between social media usage and body image evaluation.

\section{Participants and Sampling Method}

The target population for this study was university students in Malaysia. The online survey questionnaire was used in this study to collect data. Google form was used to create the survey website. The survey link of the online survey was sent to participants via social media sites such as Facebook and Twitter. The inclusion criteria of the participant are male and female students who are from 18 to 28 years old university student in Malaysia and being a competent level of English language proficiency. Therefore, they won't face any difficulty in understanding and answering research questionnaires.

The duration for completing the online survey questionnaire took around 10 minutes. Before starting the survey, participants had to go through the consent form which is on the first page. In the consent form, it was informed to participants that their participation is voluntary and anonymous and the information will be kept confidential. After participants agree, then they were directed to another page to fill in their demographic data, followed by Social Media Intensity and Body Image Evaluation questionnaire.

After screening the data, incomplete questionnaires 
were excluded and the total number of 316 participants were considered for this study.

\section{Instruments}

\section{Demographic data}

Demographic data were used to collect information from participants who participated in this study. This allowed researchers to gather background information of participants, and also know whether are they part of the targeted sample. In this section, participants are required to fill in their gender, age, marital status, ethnicity, and education level.

\section{Social Media Intensity}

Social Media Intensity (SMI) (Thoumrungroje, 2014) is a self-report six-points Likert scale ranging from "Not at All Active" to "Very Active". It consists of 4 items indicating how active an individual uses social media and social media activities. The SMI has an internal consistency of Cronbach's Alpha .84. Thus, making this test to have good reliability.

\section{Body Image Evaluation}

To measure the degree to which participants were satisfied with their body image, (Mendelson et al., 2001) Body-Esteem Scale for Adolescents and Adults was used. Participants responded to a 23 -item scale that assessed general feelings about appearance, weight satisfaction, and attributions of positive evaluations about one's body and appearance to others. The measure used a Likert-type response format ranging from 1 (strongly disagree) to 5 (strongly agree). This scale showed an acceptable internal consistency of Cronbach's Alpha .81.

\section{RESULTS}

The data collected from the survey were analyzed using SPSS software. Descriptive analysis was used to explore the frequency of gender, marital status, ethnicity, and education level. Normality test was then used to detect outliers in the data. Pearson Correlation was used to test the correlation between social media and body image evaluation.

The demographic profile in this study includedgender, age, marital status, ethnicity, and education level. The frequency and valid percent of three of the variables are shown in Table 1. In this study, $219(69.30 \%)$ of participants were undergraduate students and 97 $(30.70 \%)$ were studying at postgraduate level in Malaysian universities. The age of participants was ranged from 18 to 28 years old and the average was 23.5 years old.

Table 1: Frequency Distribution of Demographic Variables $(N=316)$

\begin{tabular}{|c|c|c|}
\hline Characteristic & Frequency & Valid Percent \\
\hline \multicolumn{3}{|l|}{ Gender } \\
\hline Male & 118 & 37.35 \\
\hline Female & 198 & 62.65 \\
\hline \multicolumn{3}{|l|}{ Marital Status } \\
\hline Single & 233 & 73.73 \\
\hline Married & 79 & 25 \\
\hline Divorced & 4 & 1.27 \\
\hline \multicolumn{3}{|l|}{ Ethnicity } \\
\hline Chinese & 138 & 43.67 \\
\hline Malay & 113 & 35.76 \\
\hline Indian & 65 & 20.57 \\
\hline
\end{tabular}

The outcomes of Pearson Correlation analysis showed that there is a significant and negative correlation between social media use and body image evaluation $(r=-0.31, p<0.001)$. The correlation is considered as medium correlation strength. The correlation is negative; indicating that if social media usage increases the body image evaluation level will be decreased. In another word, if the person uses social media intensively, he or she will have a lower evaluation of his or her body image. It is important to consider that this relationship is not a cause and effect. Table 2 shows the statistics of Pearson Correlation test for the correlation between social media usage and body image evaluation in participants of the study.

Table 2: Pearson Correlation Between Social Media Usage and Body Image Evaluation ( $N=316)$

\begin{tabular}{|l|c|c|}
\hline \multicolumn{3}{|l|}{ Body Image Evaluation } \\
\hline & Pearson Correlation & Sig. (2-tailed) \\
\hline Social Media Usage & $-0.31^{* *}$ & 0.001 \\
\hline$* * p<.01$ &
\end{tabular}

\section{DISCUSSION}

The result of the current study showed that there is a negative correlation between social media usage and body image evaluation. The result can also be supported by social comparison theory. When 
individuals engaged in social comparison, they find a lot of differences between themselves and others. Young people look at their weaknesses when comparing themselves with their peers or people in the same age groups of themselves.

Young students follow celebrities, models, athletes, or other public figures on social media and the make an ideal body image meaning and they dream to have the same bodies which look ideal from the public perspective. This comparison will make them to not be satisfied with their body and they evaluate their body image negatively.

\section{CONCLUSION}

The study findings are in line with the previous study by (Meshioye, 2016), which stated that media has an impact on body image on young adults. Moreover, the findings are consistent with another study conducted by (Puglia, 2017) that examine the effect of social media on body esteem among young women.

Social media has already pressurized many adults or even teenagers to achieve the "ideal" standards, causing them to feel difficult to achieve and think negatively. High exposure towards social media has been proved that ideal body shape has been defined with thinness in women and muscularity in men (Guonadottir \& Garoarsdottir, 2014). Besides, the findings of this study are supported by (Vartanian et al., 2001) that mentioned social media is one of the most influential factors that highly relates to a person's view towards body image.

\section{Implications}

This study helps to create awareness on the issue of body image evaluation in association with social media usage. Youth should be more aware that whether they are influenced by social media figures when they evaluate their body image. Body image dissatisfaction is also associated with self-esteem and mental health issue. Thus, knowing about factors associated with body image evaluation might reduce their dissatisfaction.

\section{Limitations}

There are various drawbacks to this analysis. First of all, owing to its cross-sectional nature, the analysis faces the issue of not being able to make assumptions about the causal interaction between variables. It is not clear whether intensive social media usage leads to lower body image evaluation or whether lower body image evaluation contributes to intensive social media usage.

Moreover, the present research used convenience sampling, which reduced the generalization of the research results. It was also in the online self-report form which may affect the data. Because there may be participants who answer the questions with less attention and they answer may not be trustable. This is one of the common limitations of self-report questionnaires.

\section{RECOMMENDATION}

Since Malaysia is a multi-ethnicity country, to explore the impacts on body image evaluation, a balanced number of participants from the different cultural or ethnic background can be recruited in future studies. Besides, a longitudinal design would be helpful in the determination of the direction of causality between social media usage and body image evaluation by examining changes over time.

Future study can consider adding a mediator in investigating the impact of the independent variable and dependant variable. For example, how stress level mediates the impact of social media usage on body image evaluation. This will help to further enhance the role of a person's psychological concern on their evaluation. Moreover, other questionnaires that can explore social media usage and body image evaluation in a deeper and detailed way is recommended for future studies.

\section{Conflict of Interest}

The authors declare that they have no conflict of interest.

\section{ACKNOWLEDGEMENT}

We would like to thank all the participants and those who have contributed to this study, including the UCSI University.

\section{REFERENCES}

Cash, T. F. (2004). Body image: Past, present, and future. Body Image, 1(1), pp:1-5.

Cherry, K. (2019). Social comparison theory in psychology. Verywellmind. Retrieve from: 
https://www.verywellmind.com/what-is-thesocial-comparison-process-2795872

Cramblitt, B., \& Pritchard, M. (2013). Media's influence on the drive for muscularity in undergraduates. Eating Behaviors, 14(4), pp:441-446.

De Vries, D.A., Vossen, H.G.M., \& van der Boom, P.K. (2018). Social media and body dissatisfaction: Investigating the attenuating role of positive parent-adolescent relationships. Journal of Youth and Adolescence, 48(3), pp:527-536.

Grabe, S., Ward, L. M., \& Hyde, J. S. (2008). The role of the media in body image concerns among women: A meta-analysis of experimental and correlational studies. Psychological Bulletin, 134(3), pp:460-476.

Guonadottir, U. \& Garoarsdottir, R. B. (2014). The influence of materialism and ideal body internalization on body-dissatisfaction and bodyshaping behaviours of young men and women: Support for the consumer culture impact model. Scandinavian Journal of Psychology, 55(2), pp:151-159.

Heiman, T., \& Olenik-Shemesh, D. (2018). Predictors of vyber-victimization of higher-education students with and without learning disabilities. Journal of Youth Studies. 22(2) pp:205-222

Hogue, J. \& Mills, J. S. (2019). The effects of active social media engagement with peers on body image in young women. Body Image, 28 (28), pp:1-5.

Kennedy, B. P. (2000). Masculinity, eating and exercise: The relationship of men to their bodies. Dissertation Abstracts International, 61(1), pp:535.

Khodabakhsh, S. \& Siak, S. L. (2018). Relationship between online and face-to-face connectedness and general health among undergraduate students in Malaysia. Malaysian Online Journal of Counseling, 5(1), pp:1-10.

Khodabakhsh, S.; Rezaei, S.; Rosli, N.A.; Chaudhry, Z. (2020). A preliminary Study on Association between demographic variables (gender, type of student and program) and level of internet use, Paper presented at the $3^{\text {rd }}$ Applied Psychology Research Conference, Kampar, Malaysia, 9 April 2020. In press: ISBN: 978-967-2244-05-9.
Kietzmann, J. H., Hermkens, K., McCarthy, I. P., \& Silvestre, B. S. (2011). Social media? Get serious! Understanding the functional building blocks of social media. Business Horizons, 54(3), pp:241251.

Kim, J. W., \& Chock, T. M. (2015). Body image 2.0: Association between social grooming on Facebook and body image concern. Computers in Human Behaviour, 48(1), pp:331-339

Manning, J. (2014). Social media, definition and classes. In K. Harvey (Ed.), Encyclopaedia of social media and politics (pp: 1158-1162).

Mellor, D., McCabe, M., Rocciardelli, L., Yeow, J., Daliza, N., \& Hapidzal, N. F. (2009). Sociocultural influences on body dissatisfaction and body change behaviours among Malaysian adolescents. Body Image, 6(2), pp:121-128.

Mendelson, B. K., Mendelson, M. J., \& White, D. R. (2001). Body-esteem scale for adolescents and adults. Journal of personality assessment, 76(1), pp:90-106.

Meshioye, A. (2016). Influences social media has on body image, anxiety and self-esteem in young adults. Retrieve from: https://www. semanticscholar.org/paper/Influences-socialmedia-has-on-body-image \% 2C-anxietyMeshioye/d9791d0b6b79c68ec9655c3609aae3f23 e895766

Muhlheim, L. (2019). Body image and eating disorders. Verywellmind. Retrieve from: https://www. verywellmind.com/body-image-and-eatingdisorders-4149424

Oakes, K. (2019). The complicated truth about social media and body image. $B B C$. Retrieve from: https://www.bbc.com/future/article/20190311how-social-media-affects-body-image

Pew Research Centre (2018). Teens, social media \& technology. Retrieve from: https://www. pewresearch.org/internet/2018/05/31/teens-socialmedia-technology-2018/

Puglia, D.R. (2017). Social media use and its impact on body image: the effects of body comparison tendency, motivation for social media use, and social media platform on body esteem in young 
women. https://cdr. lib.unc.edu/concern/ dissertations/xk81jm13m

Silva, M.L.A., Taquette, S.R., \& Coutinho, E.S.F. (2014). Senses of body image in adolescents in elementary school. Rev. Saude Publica, 48(3).

Thoumrungroje, A. (2014). The influence of social media intensity and ewom on conspicuous consumption. Social and Behavioral Sciences, 148, pp:7-15.
Vartanian, L. R., Giant, C. L., \& Passino, R. M. (2001). Comparing mass media, interpersonal feedback and gender as predictors of satisfaction with body thinness and muscularity. Social Behavior and Personality, 29(1), pp:711-723.

You, S., \& Shin, K. (2019). Body esteem among korean adolescent boys and girls. Sustainability, 11(7), pp: 2051. 